\title{
A HISTÓRIA E A INTERPRETAÇÃO ARQUEOLÓGICA- o caso do sítio PRCT05-99
}

André Essenfelder Borges'

Em decorrência das obras de captação de águas do Rio Iraí, concluídas na região metropolitana de Curitiba em 1999, realizou-se o Projeto de Operações Arqueológicas de Resgate nas áreas da barragem e reservatório do rio, como determinam a lei n ${ }^{0} 3.924 / 61$ e a Resolução n.001/86 do Conselho Nacional de Meio Ambiente ${ }^{2}$.

Durante o desenvolvimento dos trabalhos de Resgate foi localizado um conjunto de cinco sítios arqueológicos distribuídos em uma área de $14 \mathrm{~km}^{2}$, tendo sido constatada em um desses locais uma reocupação; portanto dois sítios estavam sobrepostos em um mesmo local. A dinâmica de reocupação do mesmo espaço pode ter sido uma consequiência de fatores geográficos e ambientais propícios. Este sítio (PRCT 05-99) foi metodicamente escavado e analisado durante o desenvolvimento do projeto. (BLASI et. al., 2000)

As fontes abordadas no presente artigo são séries de vestígios da cultura material de duas populações pré-históricas representadas como Tradição Umbu e Tradição Itararé, tendo sido encontrados em um local que apresentou indícios de reocupação: vestígios como pontas de projéteis confeccionadas por caçadorescoletores (Umbu), aparecem associados a habitações subterrâneas e a cerâmica tipicamente Itararé. As fontes escritas, históricas e etno-históricas, por sua vez, são interpretadas com o objetivo de esclarecer a dinâmica de ocupação, reocupação e das migrações e deslocamentos destes povos.

Uma primeira parte deste artigo discute aspectos teóricos acerca das fontes da cultura material, esclarecendo o que vem a ser um sítio arqueológico. Em uma segunda parte será feito um rastreamento etnográfico e histórico destas populações, que habitavam covas e possuíam técnicas ceramistas, identificadas como a Tradição Itararé. Também serão discutidas as primeiras versões brancas da histórica sobre o modelo de habitação e sobre as populações que as utilizavam; assim como as primeiras notícias históricas da região onde foi encontrado o sítio PRCT 05-99, e as primeiras populações brancas e colonizadoras da área.

\section{FONTES DA CULTURA MATERIAL}

\footnotetext{
${ }^{1}$ Graduaçāo História/UFPR

${ }^{2}$ Os resultados obtidos se encontram no Relatório Final de julho de 2000 do Projeto das Operações de Resgate nas áreas da barragem e reservatório do rio Iraí- Região metropolitana de Curitiba. O Projeto teve a coordenação de Oldemar Blasi e participação de Antonio Carlos Mathias Cavalheiro e Almir Pontes Filho.
} 
Todos nós, quando freqüentamos a escola, ouvimos o professor de história falar que só existe história depois que existe uma forma de registro, a escrita. Sendo assim, tudo o que se passou durante milhares de anos sobre a face da Terra e não ficou registrado de forma escrita não pertence aos domínios da história.

Este conceito limitado de história serviu até pouco tempo atrás, mas hoje não cumpre mais a sua função. Como então a história reage às descobertas arqueológicas de cerâmica ou pontas de projéteis no território brasileiro? Como a História pode contar uma história do que não é de seu domínio? Enfim, como fazer a história dos povos sem história?

A História, enquanto disciplina que privilegia o estudo da mudança social, pode contribuir significativamente para o enquadramento da cultura material na experiência humana; por outro lado, não parece estar especialmente habilitada a fornecer instrumentos para o trabalho com sua manipulação documental. Sendo assim, a interdiciplinaridade é absoluta necessidade no campo dos estudos da cultura material.

Henri Moniot nos diria que a exclusão de tantos fatos e povos é decretada inicialmente por uma idéia já adquirida de que estes povos não fizeram nada de notável, nenhum produto durável, antes da chegada dos brancos e da civilização - a selvageria como pré-história anônima e bronca, um dos estereótipos justificadores do "fardo branco". Um passado tão mal conhecido, em seus fatos e ritmos, pede que organizemos seus dados em função de concepções emprestadas (inspiradas pela rigidez teórica das diversas escolas antropológicas, pela "teoria indígena" dos informadores, pela história das sociedades mais conhecidas), ou de um arranjo bastante empírico de dados provisórios das fontes.(Novos Problemas p.109)

Entre outras características, a história dos povos sem história assume aquela de ser eminentemente uma ciência de campo. As fontes orais, o material etnológico, tudo o que se encontra inscrito nas memórias e nos comportamentos não pode ser recolhido, mas pode ser discernido, medido, avaliado e criticado, desde que segundo a ótica da sociedade estudada. Porém são ricas as obras de eruditos que praticaram um lento reconhecimento destas práticas sociais, o que consiste em deixar falarem por si os problemas e os fatos. Esta idéia está implícita nos métodos da "microssociologia", que trocava a interrogação dos informadores pela observação dos atores, decifrando "dramas sociais" (Novos Problemas p.108/9)

É dada ênfase à contextualização e à dicotomia entre fontes materiais e escritas. O que importa na abordagem documental é não isolar os documentos do conjunto de monumentos de que fazem parte. Sem subestimar o texto (que exprime superioridade, não do seu testemunho, mas do ambiente que o produziu, monopolizando um instrumento cultural de grande porte), pode-se recorrer ao documento arqueológico, sobretudo àquele método de estudo estratigráfico, iconográfico; às provas que fornecem métodos avançados da história ecológica, que fazem apelo à fenologia, à palinologia. Tudo o que permite a descoberta de fenômenos em situação (a cartografia, a fotografia aérea, a foto-interpretação) é particularmente útil. 
As fontes podem ser distinguidas em duas espécies de documentos. Primeiramente aqueles que emanam da comunicação direta dos homens entre si: eles falam, mantêm um discurso. Acreditava-se, outrora, que seria suficiente lê-los, mas também são subjetivos, distinguem-se tanto pela conivência quanto pela alteração, são de antemão portadores de uma significação definida em seu contexto de origem. E uma outra categoria: os documentos neutros e taciturnos, vestígios ou elementos materiais e imateriais nos quais o próprio historiador pode reconhecer um valor implícito de signo, índice, prova, testemunho. Um monumento tem a característica de ligar-se ao poder de perpetuação, voluntária ou involuntária, das sociedades históricas (é um legado à memória coletiva), e de o reenviar a testemunhos que só numa parcela mínima são testemunhos escritos. (Documento/Monumento p.95)

As fontes utilizadas são aquelas que não emanam da comunicação dos homens entre si. São, antes de mais nada, vestígios materiais, domínio da arqueologia, sendo esta, de todas as condutas históricas, a mais rigorosa; o melhor fiador dos progressos da história dos povos sem história. Bloch (1949: 98) diz:

"não há história sem documentos(...) Há que tomar a palavra documento no sentido mais amplo, documento escrito, ilustrado, transmitido pelo som, a imagem, ou de qualquer outra maneira"

Segundo os conceitos da Escola dos Annales, os documentos podem-se apresentar de diversas formas, entre elas as formas traduzidas em vestígios materiais, representantes da cultura da época em que tais vestígios foram fabricados e utilizados.

Foi em 1919, na extinta URSS, que Lênin fundou a primeira Escola de Estudos em Cultura Material (LE GOFF, 1998). Tal denominação deve-se à utilização, por Marx, de um termo semelhante na "Contribuição para a crítica da economia política", na qual o conceito do materialismo histórico aparece mais explícito:

Na produção social de sua existência, os homens entram em relações de produção que correspondem a um grau de desenvolvimento determinado das suas forças produtivas materiais. (...) Na base concreta (da infra-estrutura econômica) ergue-se uma superestrutura jurídica e política, à qual correspondem formas de consciência social. (BOURDÉ \& MARTIN, 1983.p.156)

O esquema marxista, como sempre, parte de um axioma: por um lado, a infra-estrutura econômica; por outro a superestrutura ideológica; e entre estes dois pólos, ligações desenham a arquitetura da sociedade.

Não é este, porém, o nosso enfoque. Pretendemos trabalhar com a noção proposta por Marx quanto às questões de abordagem da cultura material, e, simultaneamente, com certas questões propostas pelos principais nomes da Escola dos Analles (Bloch, Febvre, Braudel e Le Goff) para explicitar a noção de longa 
duração. Ao fazer uma história a partir das "coisas" ou dos objetos, qual fragmento da época ou da cultura este objeto representa?

A resposta mais provável é que o objeto representa muito pouco ou quase nada daquela cultura ou época. O que devemos levar em consideração é um conjunto de fatores e fenômenos bióticos e abióticos relacionados direta ou indiretamente àquele objeto. Assim, a história de determinada área reúne um conjunto de temas geradores, entre eles, vestígios da cultura material de épocas distintas. A possível correlação entre fontes arqueológicas apenas se torna possível no momento em que se analisam os conjuntos de fatores presentes no ambiente.

Em relação a uma sociedade "descrita"3, sem escrita ou erroneamente definida como pré-histórica (MONIOT, 1995), pode-se tentar uma leitura mais aprofundada e eficaz. Um pesquisador com uma intimidade particular com o "código cultural" presente em dada sociedade pode reutilizar e retraduzir, nessa perspectiva, os materiais manifestados nas fontes escritas compostas segundo categorias e pontos de vista ocidentais, enriquecendo desta forma uma história "compreensiva". Porém, a tomada de distância crítica que o historiador procura com relação a toda sociedade e a toda época sempre passa, entre outras necessidades, por sua apreensão da forma mais compreensível possível, sendo a forma concreta - o monumento, a ruína ou o vestígio arqueológico - tipos de documento que não apresentam interferência de discursos, mas que nem por isso são documentos neutros (Novos Problemas p.106).

O método constitui-se por diversas etapas: escolha do local, exploração, observação, análise e interpretação. São de extrema importância as interpretações vindas de outras ciências físicas, naturais e humanas. Geomorfologia, sedimentologia, pedologia, técnicas fotográficas, paleoclimatologia, paleobotânica, paleozoologia, história e antropologia cultural fornecem dados coletados através de um processo chamado "erosão regressiva", o que permite a reconstituição de alguns traços de civilizações passadas.

Os dados arqueológicos são trabalhados segundo os enfoques funcionalistas e processualistas. $\mathrm{O}$ interesse pela etnicidade provocou uma transformação na arqueologia e um novo cuidado para estudar como funcionavam as culturas préhistóricas. Os artefatos, os instrumentos ou as construções não interessam somente para pesquisas isoladas ou para classificações. Da mesma forma, o sítio não é mais encarado como lugar estanque, uma ocupação pontual no espaço vivido e construído por grupos humanos no passado (REIS, 1997).

O conhecimento do passado através dos artefatos também depende de outros componentes. Neste sentido notam-se, entre as teorias do padrão de assentamento, as denominadas "áreas de atividades", representando um grande

\footnotetext{
${ }^{3}$ Sociedade descrita designa uma diferença em relação à sociedade escrita. Alguns grupos relataram sua sociedade no passado através da escrita, porém outras não detêm este conhecimento simbólico; portanto não nos deixaram documentos escritos, mas sim documentos que possibilitam apenas uma descrição da sociedade segundo seus vestígios materiais.
} 
desafio para a pesquisa arqueológica dos assentamentos num determinado território. Além disso, a complexidade aumenta quando se constatam mudanças locacionais dentro de um assentamento. Contudo, as causas que levam às decisões de mudança não podem ser investigadas somente segundo os fatores ecológicos ou econômicos, mas devem ser concretamente encontradas nas características dos vestígios materiais. Fatores sociais, políticos e religiosos são também causas destas transformações. Assim, as conexões de transformação são refletidas no padrão de assentamento que demonstra como um povo viveu e se constituiu em um espaço (REIS, 1997).

Portanto, o sítio arqueológico se define como sendo um local onde se encontram vestígios de culturas passadas, assim como o local físico ou conjunto de locais onde membros de uma comunidade viveram, garantiram a sua subsistência e exerceram suas funções sociais em um dado período de tempo. Qualquer definição sobre sítio arqueológico estará incompleta, se não for levada em conta a sua relação com o ambiente com o qual seus habitantes estavam em contato (CHANG,1976). Conclui-se desta forma um rol de possibilidades relacionáveis diretamente imbricado com as conexões propostas para a arqueologia dos assentamentos: a ecologia e sua exploração/modificação pelas sociedades antigas; as técnicas de subsistência e a relação com os artefatos e as atividades desenvolvidas por estas populações; o povoamento; as casas, construções e função das mesmas (sendo implícitos os dados quanto à demografia, comunidade, sociedade e assentamento); tecnologia dos grupos, métodos e técnicas de manufatura; função dos objetos da cultura material, com conseqüente inferência acerca da sociedade e da divisão do trabalho, baseada na análise de tais objetos; ideologia das populações; arte; cerimonialismo, enterramentos, crenças e religião; problemas de difusão e contato interétnico, especialmente nos aspectos de aceitação ou rechaço; além dos tipos e modelos culturais vistos desde a própria comunidade.

\section{A ANALOGIA ETNOGRÁFICA}

Desde os finais do século XIX a utilização da analogia etnográfica vem acontecendo na pesquisa arqueológica. Visando à "reconstrução" do que se passou, os arqueólogos buscaram na etnografia e na etnologia uma base conceitual e documental.

$\mathrm{Na}$ arqueologia norte-americana, desde seu início até seu posterior desenvolvimento, o uso da analogia esteve bem presente e tendendo fortemente a enquadrar a pesquisa arqueológica dentro da antropologia. A arqueologia européia, desde a segunda metade do século XIX, utilizou freqüentemente a analogia por força da influência do Evolucionismo Cultural. No começo do século $\mathrm{XX}$, com o abandono do evolucionismo teórico, aportes vindos da Escola Histórico-cultural Alemã continuaram instigando os arqueólogos europeus ao uso da analogia. Desde o período do pós-guerra, porém, tenderam para uma quase total resistência ao uso da 
analogia, uma vez que se tomou consciência acerca das orientações que manipularam os dados etnográficos em favor do etnocentrismo e da superioridade racial. Mais recentemente, houve um rechaço do uso da analogia, sendo condenada até como perniciosa e impossibilitada de se conjugar ao trabalho arqueológico (FRANCH, 1989; JORGE, 1987; HODDER, 1982).

Para a possibilidade da aplicação de analogias, deve-se ter claro que a etnologia compõe um quadro teórico e a etnografia um conjunto de experiências descritivas. Ambas orientam a arqueologia, visando a amplas comparações de entidades sócio-culturais, ou a comparações pontuais advindas de relatos etnográficos específicos. O método vem do entrelaçamento dos dados arqueológicos e etnográficos numa área estabelecida, estudando-se casos compilados pela etnografia e etnologia que possibilitem a formulação de hipóteses para uma específica pesquisa arqueológica.

É importante estabelecer que analogia não é mera comparação ou demonstração de semelhanças formais ou quantitativas entre entidades e fenômenos, o que caracteriza exemplos. Entende-se analogia como demonstração das semelhanças de relações firmadas entre distintos fenômenos ou entidades (REIS, 1997).

As semelhanças de relações que propiciam as analogias requerem a montagem de um conjunto de análogos que correlacionem unidades culturais, lingüísticas, econômicas, sociais e religiosas:

(...) primeiro, examinar as fontes etnográficas em busca de correlações formais que possam observar-se arqueologicamente; em seqüência, dado o postulado de identidade de comportamento nos dois contextos (etnográfico $e$ arqueológico) $e$ as correlações etnográficas, estabelecer uma série de hipóteses de predição sobre a correlação entre o fenômeno arqueológico análogo ao etnográfico e outros fenômenos arqueológicos observáveis, que em princípio não pareciam ter relação com o etnográfico. Por último, contrastar tais hipóteses para estabelecer, em termos probabilísticos, a verdade do primeiro postulado. (MARTÍNEZ, 1994. p.241)

Os primeiros colonizadores, além de obterem contato com ameríndios da região, descrevem-nos quanto ao espaço ocupado e principais traços culturais. Estes relatos compõem as referências etnográficas dos grupos que habitavam no Primeiro Planalto Paranaense, e apresentam problemas de identificação e classificação étnica quanto aos grupos Guayaná, Gualachos, Coroado, Kaingáng e Xókleng. Outras populações brancas que tiveram contato com estas culturas indígenas foram os castelhanos, que durante o século XVI ocuparam boa parte do atual território do Paraná. Diversas cidades espanholas foram fundadas. Ciudad Real e Villa Rica del Spiritu Santu foram grandes centros populacionais, chegando a ter cerca de trinta mil habitantes. Outra característica da ocupação castelhana foram as missões ou reduções, controladas por padres da Companhia de Jesus que nos deixaram farta documentação histórica: relatos do cotidiano destas reduções, acordos de paz, 
nomes, mapas e fatos importantes que mostram as relações sociais da época colonial.

\section{AS FONTES ETNO-HISTÓRICAS}

Depois de recolhidos vestígios e informações durante a escavação do sítio PRCT-05/99, efetuou-se um confronto entre as fontes materiais encontradas e os relatos escritos sobre os vestígios semelhantes encontrados no passado. Portanto, são estas fontes escritas que irão comprovar e explicar, ou não, os dados adquiridos através das fontes materiais.

Grupos indígenas análogos são identificados pelos europeus com vários nomes: Guaranaguaçu, Obacoatiara, Guaianá, Gualacho, Tinguy, Kaingáng e Xókleng, são populações que têm características culturais muito semelhantes no que diz respeito a vários fatores: as características da habitação, a mobilidade e distribuição dos grupos pelo território, a estocagem de alimento, o tipo de recurso alimentar de que se utilizam, as ritualizações de culto aos mortos, a cerâmica, os utensílios, os mitos e as danças.

$\mathrm{O}$ vestígio mais singular encontrado no sítio foi a forma arquitetônica da habitação. Segundo um relato de Fernão Cardim, feito em 1625, o padrão de habitação subterrânea encontrava-se presente em outras diversas regiões do país:

Outros que chamam Obacoatiára, estes vivem em ilhas no rio São Francisco, têm casas como cafonas debaixo do chäo;(...) outros que chamam Guaranaguaçu, vivem em covas, têm outra língua. (CARDIN, 1930)

É importante perceber a diferenciação que o autor estabelece quanto a "têm outra língua". O tronco lingüistico mais conhecido pelos brancos durante a colonização era o Tupi-Guarani. Ter outra língua no ano de 1625 , significa não falar o Tupi-Guarani. Sabemos que troncos lingüisticos diferentes deste ocorriam no norte do país, tendo as regiões centro-sul grande número de indígenas falantes do tronco lingüistico Macro-Gê, a mesma língua utilizada pelos Kaingáng/ Xókleng em períodos históricos, e possivelmente utilizada pelos grupos de Tradição Itararé.

Em carta ânua das Missões do Paraná e Uruguai, relativa ao ano de 1633, escrita pelo Padre Pedro Romero:

Reducciones del Acaray e Iguazu (...) vienen alguna vez los gualachos que estan en las cabeçadas del Uruguai e Iguazu (...) En estos dos pueblos de gualachos que el P vio y otro tercero que está alli cerca de haver hasta quarenta familias y no mas. Su habitacion es una casa redonda hecha a manera de un horno como nos aposentos nuestros. En estas casas no tienen cosa de substancia e extima. Lo poco que tienen está escondido en el monte (CORTESÃO, 1951: .50/51). 
Romário Martins, em 1937, descreve os Tinguy, que dominavam os campos de Curitiba na encosta ocidental da Serra do Mar:

Tindiquera é a antiga denominação da actual Villa de Araucária, e quer dizer: "buraco de tinguy", pois estes indios tinham o costume, como os Guayanazes, de construir suas habitações em covas abertas no chão, em pleno campo (MARTINS, 1937).

Quando à prática da construção da habitação, descreve Mabilde, entre 1836 e 1866:

Os filhos dos coroados ${ }^{4}$, tanto do cacique principal, como dos demais individuos da tribo, vivem e habitam nos ranchos dos pais até uma idade, (...) Chegando a essa idade, sendo filho do cacique principal, este manda um indigena da tribo ajudar seu filho a fazer um rancho que sempre é de forma semicircular,(...) Os filhos dos demais coroados são ajudados pelos próprios pais para fazerem seus ranchos. Esses têm, todos indistintamente, a mesma forma. Os ranchos são colocados, sempre que possível, nas imediações do rancho dos pais. (MABILDE, 1983. p.50-52)

É interessante notar a importância do padrão de habitação subterrânea, principalmente nos períodos mais frios do ano. Fato que não descarta a possibilidade de utilização de habitações de superfície em outras estações do ano.

Quanto à mobilidade dos grupos e ao seu nomadismo:

No son amigos de ocupar mucho tiempo un sítio.(...) La caza es gran parte de su alimento, y para que no se consuma toda en parte de su alimento, y para que no se consuma toda en un paraje, mudan de sítio cada dos años, porque se procree de nuevo el antiguo, que dejan batido $^{5}$ (LOZANO, 1873: 418 e 427).

Os padrões culturais destes índios construtores de habitações subterrâneas e pertencentes ao tronco lingüistico Macro-Gê se encontram espalhados, segundo relatos apresentados acima, desde o rio São Francisco até o atual Uruguai, em áreas de campo ou próximos a vales de rios. Segundo Urban, (1992), que parte de informações lingüísticas, existe uma origem histórica comum para os falantes da família Gê; separações sucessivas e com datação antiga teriam acontecido:

\footnotetext{
${ }^{4}$ São chamados coroados os ameríndios que raspavam o topo da cabeça na forma de coroa, o que também sugere um contato com as Reduções Jesuíticas.

${ }^{5}$ Existem autores que têm certas ressalvas às definições das relações sociais de nomadismo, para estes o fato de haver migração para outros territórios pode ser mais complexo do que a idéia de manutenção do ecossistema. 'Os resultados obtidos se encontram no Relatório Final de julho de 2000 do Projeto das Operações de Resgate nas áreas da barragem e reservatório do rio Iraí- Região metropolitana de Curitiba. O Projeto teve a coordenação de Oldemar Blasi e participação de Antonio Carlos Mathias Cavalheiro e Almir Pontes Filho.
} 
A primeira separação teria ocorrido entre os Gê meridionais (Kaingáng/Xókleng) e o resto. Estes teriam iniciado sua migração em direção ao sul nesse momento, há três mil anos, mas não se tem idéia de quando teriam chegado à região que atualmente ocupam no sul do Brasil. Tampouco se sabe porque migraram, embora um estudo de relevo geográfico mostre que se dirigiam a uma região de planalto semelhante ao seu habitat originário (URBAN, In: CUNHA, 1992).

O que mantém a existência destes índios durante todo o percurso migratório é a íntima relação com o ambiente. A base da "economia" é a coleta de vegetais espontâneos e sazonais, como o fruto da Araucária, além da caça, pesca e horticultura.

A distribuição das atividades pelas estações do ano, buscando aproveitar os recursos disponíveis nas distintas ecologias, apresenta-se da seguinte maneira: na primavera preparam e semeiam produtos agrícolas perto da aldeia; no verão saem para pescar ao longo dos arroios e rios distanciados da aldeia; no outono recolhem os pinhões(...); no inverno talvez haja pouca atividade e vivem, então, das provisões feitas e dos produtos agrícolas. A maior parte das atividades de colheita e caça não tem uma época determinada(...)(BECKER, 1975).

Quanto à utilização de artefatos líticos, existem diferenças nas peças confeccionadas por populações caçadoras-coletoras em relação às produzidas por povos ceramistas. Como descreve Fernandes, em 1941:

Há notícias do uso feito pelos seus antepassados de machados de pedra (pobéng), Telêmaco Borba ainda pode comprovar a existência desses machados líticos, eram os poucos utensílios primitivos dos quais dispunham os Caingangs, no fim do século passado. (...) Há alguns anos, afirmam os índios mais velhos, encontrava-se ainda no Chapecó pequenos pilões de pedra (craie) com as respectivas mãos, substituidas hoje pelos pilões de madeira. Eram verdadeiros almofarizes de pedra, e de diversos tamanhos.(FERNANDES, 1941. p.186)

Neste relato há referência da utilização de um machado de pedra e uma mó de pedra polidos pelas populações Kaingáng. A observação de Fernandes se torna útil para caracterizar utensílios intrusivos nos sítio Itararé, ou seja, que não pertencem a esta tradição. No sítio PRCT05-99, foram identificados um "quebrador de coquinhos" e uma lâmina de machado registrada com o número 17, fazendo parte da coleção 33, Registrada no livro Tombo do Museu de História Natural do Capão da Imbuia, em Curitiba.

Quanto ao armamento, assim descreve Mabilde:

As armas usadas pelos Coroados são o arco, a flecha e o varapau.(...) fabricam seus arcos geralmente com madeira das mudas novas ou vergônteas de ipê preto.(...) Em 1835 vi 
algumas tribos daqueles selvagens que ainda se serviam das pedras silicosas, feitas cunhas, para este serviço. (...) Acabavam o aplainamento com uma lasca de sílex ou calcedônea(...) (MABILDE, 1983. p.138).

Nos sítios vinculados à Tradição Itararé não há ocorrência de pontas de projéteis confeccionadas em pedra. Estas populações ceramistas se utilizavam de lascas simples e sem retoques para dar acabamento a peças de madeira, sendo as pontas de projéteis possivelmente confeccionadas com este mesmo material.

Quanto às características da cerâmica Itararé, Loureiro Fernandes, em seu contato com os índios do Toldo de Lontras identifica algumas características da cerâmica dos Kaingáng:

Faziam assim panelas de barro (KuKrô) destinadas ao uso doméstico, em cuja morfologia predomina o bojo esférico, tendo a abertura superior circunscrita por um colo com a borda livre ligeiramente revirada para fora, determinando a formação de um sulco na face externa da vasilha.(FERNANDES, 1941, p.191)

Quanto à ocupação do espaço, descreve Mabilde:

Os pinheirais em que os índios tem seu alojamento são repartidos e divididos em territórios correspondentes, em tamanho, ao número de indivíduos que componham as tribos. Cada tribo subordinada com o seu chefe tem seu alojamento particular, em território que lhe é indicado pelo cacique principal.(...) $O$ limite entre um e outro território é assinalado na casca de um pinheiro que serve de marco de divisa. A casca é cortada com um machado de pedra, para fazer a marca de cada tribo, (...) Essas marcas são de várias formas e feitios (MABILDE, 1983. p.126).

O espaço que cada grupo ocupava varia, sendo difícil estabelecer uma regra para todos. Porém, a ocupação do espaço efetuada pelas populações Itararé é complexa no que diz respeito a sua mobilidade e área de influência. As teorias sobre os padrões de ocupação levam em consideração as áreas de atividade utilizadas por estas populações. Seriam estas as áreas de entorno das habitações, e que, em alguns casos, podem chegar a quilômetros de distância da habitação principal. Assim, podemos considerar que as áreas de atividade, a mobilidade e os deslocamentos constituem os principais fatores para a formação de caminhos que ligam as habitações a outras, ou a locais específicos.

Em relação aos mitos destas populações, Hanke (1947) apresenta um trecho de um mito coletado no posto indígena de Duque de Caxias, no Estado de Santa Catarina, entre os rios Hercilio e Plate, formadores do rio Itajaí. O trecho foi citado por dois velhos índios que cantaram, num idioma antigo, este mito de origem, passado de pai para filho por inúmeras gerações: 
El padre, este padre Djuwai, este salió del interior de la tierra, salió como primero. De la tierra salieron los primeros hombres llegando a la costa del mar. Estaba todo bién. Los primeros hombres llegando a la costa del mar hacian fiestas y bailaban. Bailaban los primeros hombres que han salido del interior de la tira. Kyie salió del interior de la tierra, era uno de los primeros, saliendo de la tierra como los primeros.

Encontraban maiz, sembrando ya para ellos. (HANKE, 1947. p.86-87)

Ainda em relação aos mitos, existem referências sobre a Serra do Krijijimbé, representada na mitologia Kaingáng como um divisor em relação à ocupação do espaço e à separação de membros indígenas. Estas divisões ficam bem claras na lenda sobre o Dilúvio Kaingáng contada por Romário Martins em sua obra Paiquerê. Ela também é citada por Borba (1908), que reconhece a Serra do Krijijimbé como sendo a Serra do Mar.

\section{A OCUPAÇÃO EUROPÉIA}

Alguns dos antigos caminhos utilizados por estes índios foram utilizados para facilitar o contato com o branco, transformando-se em caminhos coloniais. Em síntese, os caminhos pré-cabralinos, após serem tecnicamente planificados, tornamse trilhas para muares e até estradas (HOLANDA, 1994; MOREIRA, 1972, 1975; CHMYZ, 1995, 1996, 1999).

A abertura da estrada de tropas, ligando Rio Grande a São Paulo, em 1728, e o surgimento de Lages, Curitibanos, Curitiba e Guarapuava praticamente vieram a impedir que os Xókleng continuassem a fazer suas incursões de coleta nos ricos pinhais que se adensavam no entremeio dos campos. Durante o primeiro século de colonização os Kaingáng e os Xókleng refugiaram-se nas encostas do planalto e nos vales e afluentes do rio Paraná, ficando assim protegidos por matas de araucária e mata subtropical. A marcha da "civilização" branca pelo sul da colônia modificou drasticamente a vida dos Xókleng, reduzindo sua área de perambulação, que quase desapareceu por completo, havendo hoje em dia poucas e pequenas reservas indígenas em nosso estado (SANTOS, 1973).

Alguns locais antes ocupados por estes índios permaneceram inalterados, como no caso do sítio PRCT05-99. Devido à busca por recursos alimentares, a área de influência do sítio-acampamento certamente teria uma malha de caminhos antes utilizados por estes índios. Um deles, o mais próximo, passou a se chamar Caminho do Itupava, no período colonial (caminho que se encontra na área de influência do alagamento da barragem do Iraí).

A origem do caminho remonta a uma lenda indígena, segundo a qual dois caçadores seguem uma anta em disparada, começando a perseguição no Planalto e só terminando, com o animal morto, em Porto de Cima. A lenda, provavelmente uma invenção do paranismo, é descrita por Antonio Vieira dos Santos, no ano de 1851 . 
Uma outra analogia documental pode ser baseada nos relatos da expedição de Martin Affonso de Souza (MARTINS, 1937). Em dezembro de 1530 parte de Lisboa Martin Affonso de Souza, fidalgo da Casa Real, para inaugurar a primeira colônia regular no Brasil; em abril de 1531, fundeava no Rio de Janeiro. A expedição propunha o reconhecimento da costa sul até a bacia do Prata. Assim que aporta em Cananéia encontra o bacharel Francisco Alves, degredado português, deixado no Brasil em 1501 pela esquadra de André Gonçalves. O bacharel propõe a Martin Affonso conceder-lhe uma bandeira com 80 homens com o fim de the trazer do interior do país, dentro de 10 meses, quarenta escravos carregados de ouro e prata. Esta expedição jamais voltou.

Outra expedição, a mando de Pero Lobo, ultrapassou a Serra Geral, a sul da Serra Negra (próximo a Guaraqueçaba), e chegou às nascentes do Goyo Covó, onde se deu o encontro com os índios. No fim a expedição de Martin Affonso segue viagem ao rio da Prata, tendo um dos barcos da esquadra naufragado no estuário. Volta ao norte e acaba por fundar a vila de São Vicente, em 20 de janeiro de 1532 (MARTINS, 1937: 12 -13).

Antonio Vieira dos Santos, no ano de 1850, escreve sobre a ocupação do território pelos mineradores de ouro desde o ano de 1555. Relata:

(...) abriram-se estradas e comunicações com o planalto para a exploração de ouro seguindo o caminho do Arraial que parte do porto Padre João da Veiga no rio do Pinto. Passava pelo pão vermelho, pelo terreno das lavras chamadas do Pantanal e Limoeiro de onde subiam os morros do Brejautuba, de Serra Velha da Fortuna, do Páu Ôcco, e do Palmital saindo no lugar denominado ainda hoje o Arraial (SANTOS, 1850: 12).

A exploração continua a ser efetuada por estes mineradores nos rios de Serra acima até meados de 1600 , quando então se relata a fundação de uma vila nas margens do rio Atuba (MOREIRA, 1972).

Um dos caminhos que faziam a ligação entre a planície e o planalto se localiza nas proximidades do sítio PRCT-05/99. No período histórico passou a ser conhecido como Caminho do Itupava, e faz a ligação entre a vila do Atuba, no Planalto, e Porto de Cima, na planície litorânea, e de lá até Morretes. Já foi chamado por diversos nomes, entre eles, Caminho do Mar; de Paranaguá; de Cubatão; Caminho Real; Grande; da Serra; de Morretes e de Curitiba.

O caminho tem início, ou fim, em frente do atual Circulo Militar de Curitiba, antigamente local chamado de Passo do Rio Belém; cruzava os rios Belém, Juvevê, Bacacheri, Atuba e Palmital, chegando até a fazenda pastoril do Canguiri, pertencente, em 1815, ao sargento-mor das Ordenanças de Antonina, Antônio José de Carvalho, e à fazenda da Borda do Campo, pertencente, até 1763, ao Capitão Valentin Teixeira de Azevedo, sendo vendida nesta data ao Capitão Anthonio Ferreira Mathoso, ambas localizadas na atual cidade de Quatro Barras. Nesta localidade existia um ramal pela região de Piraquara e outro que passava por um lugar chamado Campina, indo sair na Boa Vista, vale localizado na encosta do 
Pão de Lot, local com menor desnível em relação às montanhas próximas (MOREIRA, 1975).

Os caminhos coloniais têm características próprias. Em geral, seguem um curso definido nas passagens mais difíceis, porém, em áreas alagadiças ou em campos, os caminhos podem tomar diversos rumos; aparecem diversos ramais que voltam a se encontrar quando o terreno se modifica novamente.

$\mathrm{O}$ traçado dos caminhos passa a ser adequado às necessidades de cada época e acaba sofrendo inúmeras transformações no decorrer do tempo. No caso do Caminho do Itupava, seu traçado foi adequado ao uso entre 1649 e 1654 pela primeira vez. Em 1743, o caminho teria boas pontes de madeira, seria calçado e com estivas de troncos nos lugares alagadiços. Muitos destes reparos foram feitos devido à necessidade da passagem de armamento trazido para a conquista dos campos de Guarapuava, ocupados, na época, pelos castelhanos, e também a algum envolvimento de índios Kaingáng habitantes destes campos (MOTA, 1994).

Os Caminhos da Graciosa e do Itupava se utilizavam da mesma trilha desde a saída de Curitiba até cerca de três léguas de distância, onde então se separavam. O tenente-coronel de Engenheiros Henrique Rohan escreve ao presidente da província, Zacarias de Góes e Vasconcelos, pedindo mudanças na planificação dos caminhos em 1854, definindo-os como:

"(...)testemunho da imperícia dos que a delinearam ou um monumento da miséria dos tempos em que se construiu esta obra admiravelmente má".

Devido a isto, o engenheiro propõe as seguintes modificações:

O Caminho da Graciosa atravessa o rio Curral Falso, pouco acima de sua confluência no Irahy e vae sahir na Borda do Campo. Este alinhamento evita a volta que dá a estrada atual passando pelo Engenho do Belém no Cangoery e pela casa do Curral Falso(...) deve a nova estrada atravessar o Irahy entrar pelo campo de Piracuara e seguir dai até o cume da Serra, cortando apenas a do Ytupava em um só ponto, o Guaricoca. A dar-se a possibilidade de se poder vencer os banhados do Irahy.

Algumas informações históricas sobre a área de estudo e sobre o tipo de habitação subterrânea são encontradas em BORBA (1908), que descreve:

No logar denominado- Boqueirão- à margem da estrada da Graciosa, entre os ribeiros Cangoeri, (deve ser Acan-gue-ri, - cabeça, osso agoa) - e Timbú, existiam em nosso tempo de menino, duas destas covas; diziam os velhos d'aquele tempo, que taes covas tinham servido para moradas de bugres ou para depósitos de guardar pinhões. (...) Seria interessante proceder-se nellas a uma minuciosa escavação e busca. (BORBA, 1908: 127). 
Os rios citados por BORBA se localizam imediatamente a oeste da Serra do Mar, formando assim uma das principais nascentes do rio Iguaçu, sendo o rio Timbu diretamente afetado pela área de inundação.

Dentro da área impactada pela construção da barragem, encontramos ainda referências históricas sobre o Caminho do Itupava. Segundo Chmyz (1995), Moreira (1972) e Santos (1851), a rota do caminho seguia de Porto de Cima para as nascentes do Rio Iguaçu. Aparecem algumas descrições (no jornal O Dezenove de Dezembro (1850/55) e em Relatórios de Presidente de Província de 1854/55) de obras e até assaltos na região descrita como área de estudo.

Estes dados possibilitam a identificação de caminhos existentes antes da chegada do colonizador. Também elucidam questões sobre o processo de formação, adaptação e mutação dos caminhos ou trilhas originariamente utilizadas pelo indígena e posteriormente apropriadas e planificadas pelo colonizador, possibilidade de interpretação reforçada por HOLANDA (1994).

É importante ressaltar, como nos mostram Cardoso \& Westphalen (1986), a importância da história do território sul-americano antes da chegada das populações brancas, e, por conseqüência, a necessidade de também se trabalhar com documentos históricos não escritos (LE GOFF, 1998).

A partir destes autores, buscamos formular uma visão de conjunto quanto à formação do caminho do Itupava, levando em consideração os elementos geográficos que possibilitam a passagem da Serra; as possíveis rotas das migrações indígenas antes da conquista européia, baseadas em vestígios arqueológicos; e a escolha das rotas dos caminhos utilizados pelo colonizador. Com ênfase na rota descrita pelo Caminho do Itupava, percebemos a proximidade entre o sítio-habitação e a sua rota. Desta forma, o presente trabalho vem a discutir o grau de ocasionalidade desta "coincidência", levando em consideração seu contexto junto a agentes e atores, seus deslocamentos migratórios e as modificações efetuadas por eles.

\section{CONCLUSÃo}

O presente estudo identifica características determinantes para a ocorrência de uma reocupação em um mesmo sítio por duas populações distintas, Umbu e Itararé, em épocas também distintas, fato que nos remete diretamente às condições geográficas e ambientais da área de entorno do sítio PRCT-05/99. Quanto ao espaço ocupado, presume-se que o domínio das técnicas de confecção de utensílios cerâmicos pelas populações Itararé auxiliaria o desenvolvimento de hábitos alimentares mais diversificados, facilitando a sobrevivência do grupo, aumentando o número de indivíduos e ampliando sua área de atividade. Porém, o que não fica muito bem explicado é a área de atividade utilizada pelos grupos caçadores-coletores e pelos ceramistas. Nas informações obtidas com os cortes experimentais, percebese que o espaço ocupado pelas populações Umbu foi maior do que o espaço ocupado 
pela Tradição Itararé. Temos uma relação de proporcionalidade se compararmos a área ocupada com o número de habitante: quanto maior uma, maior o outro, em teoria. Se levarmos em consideração o número de vestígios em relação ao espaço ocupado, a primeira ocupação feita pelas populações Umbu possuía um grupo mais numeroso do que a tradição ceramista.

O estudo também evidencia uma outra forma de abordagem para o surgimento de caminhos coloniais, em especial, o do Caminho do Itupava. Esta abordagem baseia-se nas características culturais da Tradição Itararé e nos aspectos geográficos do terreno onde se inserem os sítios. Assim como os acidentes geográficos contribuíram para a ocorrência da reocupação, é possível que estas características ambientais também tenham contribuído para a formação de um caminho próximo ao sítio.

Esta questão da formação de caminhos pode ser melhor compreendida se levarmos em consideração as necessidades específicas de cada época. Antes do ano de 1500, o caminho teria um tipo de utilidade, segundo os aspectos culturais das populações Itararé. Em período histórico, este caminho é utilizado pelo colonizador segundo as suas necessidades. A mineração de ouro não requer grandes obras de reparos, porém, a partir do momento em que se faz necessário o comércio e a passagem de animais conduzindo produtos, é necessária a planificação da trilha. Assim, o caminho passa por modificações, é retificado e recebe calçamento, tornando-se um caminho colonial cuja função corresponde às necessidades da época. Atualmente, o Caminho do Itupava passa por novas reformulações que o capacitem para a utilidade turística.

Quanto aos trabalhos de resgate de vestígios arqueológicos, as questões políticas não podem ser deixadas de fora. As escavações efetuadas no sítio PRCT05/99 foram prejudicadas devido a falta de interesse dos empreendedores da barragem por esses fragmentos da pré-história brasileira. O tempo dado para o desenvolvimento da escavação foi muito inferior ao necessário para se efetuar um bom estudo. Assim a obtenção de mais dados sobre a área ficou prejudicada e limitada ao tempo oferecido pelo empreendedor.

Concluindo, gostaria de enfatizar o descaso a que estão sujeitas as áreas com relevante interesse arqueológico. A falta de conhecimento do público em geral e o crescimento populacional são os fatores que mais prejudicam o estudo arqueológico no Brasil, assim como o desenvolvimento da agricultura ou a construção de grandes empreendimentos, como indústrias, usinas hidroelétricas e barragens, que ocupam lugares que antes não eram ocupados, sendo inadmissível o fato de estes empreendedores se eximirem da responsabilidade de financiar a pesquisa científica nas áreas a serem ocupadas, como medidas mitigadoras ao impacto causado pela empresa.

\section{FONTES}


BLASI, O; CAVAlHeIRO, A.C.M. \& PONTES FILHO, A. Projeto das operações arqueológicas de resgate nas éreas da barragem e reservatório do rio IraiRegião metropolitana de Curitiba. Relatório Final, Julho de 2000.

BORBA, Telêmaco. Actualidade indígena. Impressora Paranaense. Curitiba, 168p. 1908.

CARDOSO, Jayme Antonio \& WESTPHALEN, Cecília Maria. Atlas Histórico do Paraná. Livraria do Chain Editora. Curitiba. 1986.

CHMYZ, Igor. A ocupação do litoral dos Estados do Paraná e Santa Catarina por povos ceramistas. Estudos Brasileiros. Curitiba, 1(1): 7-43. 1976.

Arqueologia de Curitiba. Boletim Informativo da Casa Romário Martins. Curitiba, 21(105): 5-55. 1995.

- Subsídios para o estudo arqueológico do vale do rio Iguaçu. Revista do CEPA/UFPR. Curitiba, 1: 31-52. 1968.

. Pesquisas arqueológicas no alto e médio rio Iguaçu. Publicações Avulsas do Museu Paraense Emilio Goeldi. Belém, 13: 103-125. 1969.

CHMYZ, I. ; PEROTA,C.; MÜLLER, H.I. \& ROCHA, M.L.F. da. Notas sobre a Arqueologia do Vale do rio Itararé. Revista do CEPA/UFPR. Curitiba, 1: 7-23. 1968.

CHMYZ, I.; SGANZERLA, E. \& VOLCOV, J.. Arqueologia da área prioritária. Projeto hidrelétrico Tijuco Alto - rio Ribeira- São Paulo - Paraná. CBA/CEPA/FUNPAR/UFPR. Curitiba, 187p. 1999.

HOLANDA, S. B. de. Caminhos e Fronteiras. Companhia das Letras. São Paulo, 1994.

SANTOS, A.V. dos. Memória Histórica da Villa de Morretes e do Porto Real, 1851.

\section{REFERÊNCIAS BIBLIOGRÁFICAS}

BECKER, Itala. Estudos sobre o abastecimento indígena. Publicações avulsas. São Leopoldo, UNISINOS/IAP n.02. 1975.

BLOCH, Marc. Apologie pour l'histoire ou métier d'historien. Colin, Paris 1949. In: Enciclopédia Einaudi, V.I - Memória-História. p.98.

BOURDÉ, G. \& MARTIN, H. As Escolas Históricas. Fórum da História.

Publicações Europa-América. Lisboa, 154p. 1983.

CARDIM, Fernão. Tratado da terra e gente do Brasil. 2a edição. Cia Editora Nacional. São Paulo. [1625] 1930.

CHANG, K.C. Nuevas Perspectivas en arqueologia. Alianza. Madrid. 1976.

CORTESÃO, J. Jesuítas e bandeirantes no Guairá 1549-1640. Manuscritos da coleção d'Angelis I. Biblioteca Nacional- Divisão de obras raras e publicações. Rio de Janeiro. 1951.

ENCICLOPÉDIA EINAUDI, Volume I- Memória- História. Documento/monumento. p.95-106. 
FERNANDES, Loureiro. Os Caingangues de Palmas., Arquivos do Museu Paranaense. Curitiba, 1: 161-209. 1941.

FRANCH, José Alcina. Arqueologia antropológica. Akal. Madrid. 1989.

HANKE, Vanda. Los índios Botocudos de Santa Catarina, Brasil. Arquivos do Museu Paranaense. Curitiba, 6: 47-106. 1947.

HODDER, Ian. The present past - an introduction to anthropology for archaeologists. B.T. Bastford Ltd. London. 1982.

JORGE, Vítor Oliveira. Projectar o passado - ensaios sobre arqueologia e préhistória. Presença. Lisboa. 1987.

LEÃO, Ermelino de. Dicionário Histórico e Geográfico Paranaense. Ed. Oficina Gráfica Paranaense. Curitiba. 1926.

LE GOFF, Jacques. A História Nova. Martins Fontes. São Paulo, 1998.

LEI FEDERAL N ${ }^{\circ} 3.924 / 86$, In; Revista do CEPA/UFPR, Curitiba, ${ }^{\circ} 1$, 1968. p'7381.

LOZANO, P. História de la conquista del Paraguay. Tomo 01. Casa Ed. Imprensa Popular. Buenos Ayres. 1:418-427. 1873.

MABLDE, Pierre F.A.B.. Apontamentos sobre os indígenas selvagens da nação Coroados dos Matos da Província do Rio Grande do Sul. Ibrasa/INL. São Paulo. [1836/1866] 1983.

MARTINS, Romário. História do Paraná. Curitiba, 1937.

MARTÍNEZ, Vítor M. F. Teoria y método de la arqueologia. Síntesis. Madrid. 1994.

MONIOT, Henri. A História dos povos sem história. p.99. In: LE GOFF, J. História: novos problemas. (org.) Jacques Le Goff e Pierre Nora. Livraria Francisco Alves. Rio de Janeiro. 1995.

MOREIRA, J. E. Eleodoro Ébano Pereira e a fundação de Curitiba à luz de novos documentos. UFPR. Curitiba, 148p. 1972.

MOTA, Lúcio Tadeu. As guerras dos índios Kaingang-1769/1924. Ed.UEM. Maringá. 1994.

REIS, José Alberione dos. Guaianá, Buraco de bugre, Kaingáng/Xokleng: qual a ancestralidade? qual analogia? de que campo pode-se falar? Revista do CEPA. Santa Cruz do Sul, 21(26). 1997.

SANTOS, Silvio Coelho dos. Índios e brancos no sul do Brasil - a dramática experiência dos Xókleng. Edeme. Florianópolis. 1973.

URBAN, Greg. A história da cultura brasileira segundo as línguas nativas. In CUNHA, Manuela Carneiro da. História dos índios do Brasil. Companhia das Letras. São Paulo. 1992. 